\title{
DESENHOS 2001-2011: ESTÓRIAS E RABISCOS
}

Isabel Baraona ESAD.CR, Caldas da Rainha, Portugal ${ }^{1}$

Breve ensaio sobre a relação entre o desenho e o texto no trabalho plástico de Isabel Baraona. Recorrendo a um conjunto variado de autores de diversas áreas de estudo, é dada especial atenção a dois elementos que são comuns a várias séries de desenhos desenvolvidas entre 2001 e 2011: a casa e corpos duplicados, como substitutos de uma auto-representação. Trata-se de uma reflexão singular sobre desenhar e o processo de criação de imagens, e sobre como o trabalho artístico pode ser uma cartografia de afinidades eletivas.

Palavras-chave: desenho, processo, auto-representação, estória, narrativa

Contam histórias os romancistas, contam histórias os dramaturgos, contam histórias os poetas, contam-nas igualmente aqueles que não são, e não virão a ser nunca, poetas, dramaturgos ou romancistas. Mesmo o simples pensar e o simples falar quotidianos são já uma bistória. José Saramago ${ }^{2}$

Apesar da auto-representação não ser o tema principal e fundador da minha produção gráfica é, ainda assim, um tema presente em várias séries de desenhos. Um primeiro momento de aparente inacção - leitura, recolha de material diverso - antecede o momento de acção e materialização da ideia. No fazer arte, a pesquisa é uma tarefa infinda, cíclica, exigente em disciplina e que obriga à observância de uma (qualquer) metodologia peculiar: seja no que concerne uma reflexão sobre o processo de trabalho, o estudo dos materiais, os temas e por fim uma atenção crítica aos resultados plásticos. As várias leituras e o estudo de certos autores pode ter uma implicação (quase) directa, embora não imediata, no trabalho prático. Embora não sejam ilustrativos, as séries de desenhos produzidas entre 2001 e 2011 nascem geralmente a partir de

$1 \quad$ Contato da autora: mail.baraona@gmail.com.

2 Saramago, José. 1997: pág 39. “O autor como narrador". In, Revista $L E R$ no 38, primavera/Verão. Lisboa. 
um texto. Faço a ressalva que as imagens que acompanham esta reflexão não têm como função explicitar as ideias-chave expostas no texto mas tão somente testemunhar diferentes experiências plásticas.

Cada série de trabalhos é construída lentamente levando, por vezes, 2 ou 3 anos até estar completa $^{3}$ e ser publicamente exposta. Os títulos gerais são uma escolha meditada, difícil e muito importante: desvelam conteúdos afectivos e conceptuais - a palavra, ou o fragmento de frase, indicia o conteúdo da estória e inicia a narração. $\mathrm{O}$ facto de ter estudado cinco anos numa outra língua acrescentou um cuidado e uma atenção à escolha da palavra: a sua ressonância, o seu significado, conotação e ambiguidade.

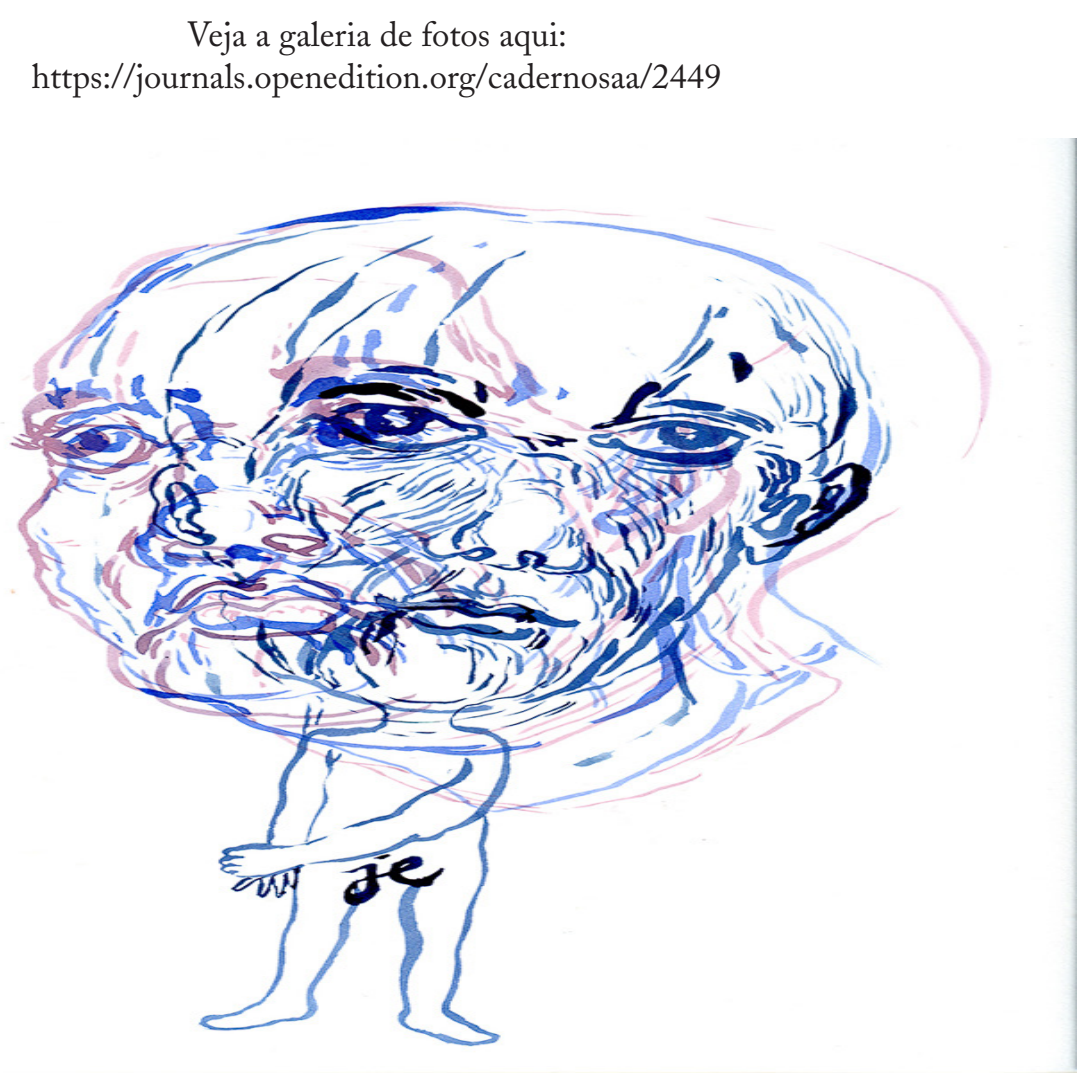

O conjunto das várias séries de desenhos, nomeadamente até 2011, caracteriza-se pela sua natureza narrativa e entrelaça indistintamente diversos fragmentos de textos literários, contos de fadas e estórias infantis, bíblicas e mitológicas, assim como episódios autobiográficos. Os textos cuja base reside na tradição oral são livremente apropriados, sobretudo as passagens relativas aos dois elementos primordiais da existência: sexo e a morte, aqui convertidos em amor e metamorfose. São também e, sobretudo, estórias de iniciação, aprendizagem, transformação efémera e transitoriedade patética. Estas narrativas têm também como tema principal as relações humanas, familiares e entre sexos opostos. Geralmente, os desenhos apresentam pequenos grupos ou, raramente, personagens isolados que vivem suspensos no espaço (aparentemente) vazio $^{4}$ da folha.

3 Trata-se de uma aferição subjectiva - que implica, por exemplo, esgotar as possibilidades do tema/palavras que deram origem aos desenhos.

4 José Gil, no preâmbulo redigido sobre as pinturas de Jorge Martins, define bem esse "vazio": "A tela branca não existe. (...) antes mesmo da mão ter delineado um traço, já o olhar sobre ela projectou miríades de pontos, 
Num mesmo desenho sobrepõem-se diferentes tempos de acção e tensão: seja isso comunicado pelo uso de diferentes riscadores ou pelo facto da narrativa, que nem sempre é inteiramente legível, parecer transpor a superfície do desenho sendo construída no verso e reverso da folha de papel. A forma de construção da narrativa é tão importante como o conteúdo: ela sublinha ou vela.

O papel é uma pele arranhada a bico de pena e, por vezes, escarificada no reverso - formando um relevo, tal gravura cega. $\mathrm{O}$ desenho nasce de um atrito (simbolicamente do meu atrito com e no mundo). Eu raspo uma superfície e ela devolve-me a imagem correspondente ao gesto; ou seja, a folha devolve-me a dose de violência que sobre ela projecto; como se o suporte já contivesse o desenho que eu, arqueologicamente, devo trazer à superfície. O papel é o suporte aparentemente frágil sobre o qual os desenhos são riscados, recortados, raspados. Estas marcas são sinais da violência concentrada na linha ininterrupta do desenho. Nestes desenhos, a pele dos personagens não é uma membrana protectora, nem é incólume; vibra como uma víscera, não há nem exterior nem interior. É uma membrana sujeita a rugas, pregas, feridas, chagas, úlceras, evocando aberturas extremamente sensíveis - boca ou uma vagina. Trata-se de corpos-carne, esfolados, sensíveis paradoxalmente tanto à dor como ao prazer do tacto; são fragmentos de um corpo com órgãos que se multiplicam e transbordam. A frase tu és paisagem, recorrente desde 2003, opera como uma declaração de amor e uma declaração de intenção transformando este(s) corpo(s) no território de um jogo sem regras, nem (auto)censura.

Em Fragmento de um discurso amoroso, Roland Barthes define, numa breve frase, a violência intensa do desejo: "há os braços erguidos por desejo e os braços estendidos da necessidade" 5 (Barthes 1977 : pág. 23). É nesta tensão que se tece o eterno equívoco presente nas relações entre os personagens. Estes entes imperfeitos sofrem na sua incompletude. Lançam-se num ímpeto de enlace aterrando o outro pelo seu excesso de afeição, estrangulando o seu objecto de desejo. A carência de um terno abraço pleno de paixão pode encerrar uma grande dose de violência e representar um ataque físico, uma asfixia - vida ou morte. Este é o abraço que pode oscilar entre o carinho e a agressão num mesmo corpo potencialmente maternal, exigente e/ou devorador. Nestes desenhos, que procuram interpretar quão difícil é desejar um outro, nenhum olhar maniqueísta censura esta violência de possessão do ente amado. E é uma distância ínfima, subtilmente traçada entre dois corpos que permite sobreviver a este pathos exultante que tanto pode ser vivido entre amantes, como por progenitores e a criança.

Cada personagem espelha na sua silhueta e aparente deformidade ${ }^{6}$, as suas características morais ou emocionais e são, por vezes, desenhados com atributos de ambos os sexos - segundo a descrição arcaica de Aristófanes:

A princípio havia três géneros entre os homens, e não dois, como hoje, o masculino e o feminino; um terceiro era composto dos outros dois: o seu nome subsistiu, mas a coisa desa-

manchas, esboços de formas e movimentos. Só o facto de a tela estar imóvel diante do pintor, e de o branco ser homogéneo e liso, induz deslocações de espaços e fantasmas de cores.” in, GIL, José (2005, pág.187) Sem Título. Escritos sobre arte e artistas. Lisboa, Relógio d’Água.

5 Tradução da autora. No original: “il y a les brás levés du désir et les bras tendus du besoin”.

6 “(..) a deformação física significa frequentemente deficiente desenvolvimento psicológico. (...) parte superior do corpo, incluindo a cabeça, é geralmente parecida com um animal, enquanto a parte inferior é a de um ser humano normal.” Bettelheim, Bruno. 1998: 93. Psicanálise dos contos de fadas. Lisboa, Bertrand Editora. 
pareceu: então, o real andrógino, espécie e nome, reunia num único ser o princípio macho e o princípio fêmea (...) (Platão 1986: 67 e seguintes)

Estes são corpos-carne, hipersexuados mas nem sempre erotizados, no sentido em que recorro a arquétipos associados ao feminino e ao masculino - lunar, esquerdo, passivo / solar, direito, activo - para questionar os papéis tradicionalmente atribuídos ao homem a à mulher. As roupas e os sapatos enfatizam e reactualizam estes arquétipos - não são simples adereços, são parte integrante das silhuetas. Por vezes os vestidos surgem cosidos nas pregas dos seios e ventre, os sapatos são desenhados na linha contínua que demarca a silhueta do corpo. Os sapatos de salto alto, por exemplo, são sinónimo de sedução e feminilidade mas também de constrangimento físico. Quem se equilibra sobre os saltos altos lida com o desejo do outro, assume uma sexualidade madura. Quem se desequilibra sobre os saltos altos entontece, numa marcha que deforma a musculatura das pernas. Fragiliza-se ou descalça-se ${ }^{7}$.

Pequenos detalhes diferenciam o papel de cada personagem mas os gestos ${ }^{8}$ (braços, mãos e pés), a posição e distância entre cada uma das figuras pode gerar ambivalência; como se todos os personagens tivessem uma alteridade latente incorporada pelo outro personagem que com ele dialoga: existe em ambos a possibilidade de uma permuta de papéis. A presença de outro comporta a possibilidade de transformação. Esse outro personagem, estrangeiro e estranho (a uma interioridade física e emocional) é uma tautolgia porque é, e será sempre, externo - um outro corpo que não o primeiro. Cada personagem pode ser, segundo os diversos contextos, uma duplicação ou um reflexo de outro personagem. Porém, escuso-me a apontar uma preferência, a designar qual foi desenhado primeiro e qual se encontra num segundo plano, ou seja, a fixar uma hierarquia entre as figuras.

Os personagens estão quase sempre em movimento, prestes a principiar ou concluir uma acção - estão suspensos entre duas etapas. E é também esta suspensão que frisa a incompletude da transformação, e pressagia que a génese da sua natureza é a imperfeição. Neste contexto, cito um excerto de Cinquenta e oito indícios sobre o corpo, belíssimo texto de Jean-Luc Nancy:

Os corpos produzem sentido para além do sentido. São um exagero de sentido. (...) o corpo não pára de se agitar. A morte imobiliza o movimento que perde forças e renuncia mexer-se. O corpo é o buliço da alma”. (2004: 17)

Estas figuras frágeis, gorduchas, inábeis, deliberadamente desenhadas de modo canhestro contestam a imposição contemporânea de beleza e a imperiosa cura de todos os males. Nancy enuncia-o dizendo do corpo que é "uma alma macia ou enrugada, gorda ou magra, glabra ou peluda, uma alma com bossas ou chagas” (Nancy 2004: 17). Os corpos destes personagens incarnam um mal-être, uma aflição de ser e estar transitoriamente suspensas na ambiguidade de um gesto, sem procurar atenuar nenhuma imperfeição, vivem e sofrem os rituais de passagem e amadurecimento. Humanizam-se sem se deixarem domesticar totalmente. Diz Barthes " $\mathrm{O}$ que eu escondo na minha linguagem, é dito pelo meu corpo (...) O meu corpo é uma criança

\footnotetext{
7 Acrescento uma outra leitura: é o mais jovem ou são de espírito que, despido e descalço, mantém uma ligação à terra e aí apoia todo o peso do seu corpo.

8 Os gestos elaborados e expressivos das figuras revelam o meu apreço pela pintura antiga e religiosa, sobretudo pelo Barroco.
} 
teimosa, a minha linguagem é um adulto muito civilizado» ${ }^{9}$ (Barthes 1977 : 54). Estas figuras, na sua candura desajeitada, colidem em/consigo próprias, cindem-se no desejo expresso involuntariamente na pose do corpo.

A natureza destes trabalhos é ambivalente, a categorização pode vacilar entre o que é considerado um desenho autónomo (de autor) e um desenho de ilustração. Esta ambivalência é conscientemente alimentada pelo carácter explícito e excessivamente narrativo das cenas, e pela tipologia dos "bonecos". É importante frisar que esta sucessão de fragmentos narrativos sobrevém em tumulto e sem um plano prévio. O que é contado e a forma como é anotado surge (quase espontaneamente) da sonoridade de uma palavra ou frase. O desenho é traçado directamente sobre o seu suporte definitivo - não existem esboços - e, quando o desenho corre mal é rasgado, vai para o lixo. Um pequeno texto redigido por Ângelo de Sousa define, com a maior exactidão, o que considero uma das características fundamentais do meu processo de desenhar: “(...) "ver”, no papel, uma forma que tentarei concretizar, tão fielmente quanto possível; necessariamente irão aparecendo outras formas e o processo vai decorrendo. É como se o "desenho" se fosse projectando na superfície do papel. Às vezes a coisa corre mal, claro.” (Sousa 2003: 196)

É um aspecto próprio ao desenho, uma certa imediaticidade que, todavia, não exclui um certo assombro por "aquilo" que aparece sobre a folha.

Há dois elementos aos quais ciclicamente retorno: a casa e o corpo feminino duplicado.

A casa é um cosmos. A casa é um duplo do corpo. Diz Al Berto em uma linha de $A$ Casa Desabitada "Uma casa, para a possuirmos, temos de nos confundir com ela" (Al Berto 2001: 71). É um arquétipo associado ao mundo feminino, simultaneamente o espaço materno acolhedor e o espaço de domesticação (castração). A casa é um território físico bem delimitado, gerido por afectos e segundo uma ordem por nós implantada: é o corpo que nos protege e abriga, seja uma casa, tenda, cabana, castelo, ovo ou casca, ou útero. Gaston Bachelard propõe que « (...) qualquer espaço verdadeiramente habitado contém a essência do conceito de casa». ${ }^{10}$ (Bachelard 2001 : 24). A casa é o palco do primeiro amor e do primeiro drama, é, por excelência o local iniciático que nos instrui sobre a sobrevivência, e que simultaneamente nos protege e atira para o mundo. Esta, a primeira, e todas as outras casas são como uma caixa de Pandora: um enigma a ser investigado, o espaço onde se revivem os dramas e se guardam os segredos. É por essa razão que, em grande parte dos desenhos feitos entre 2001 e 2011, a casa é transparente ou "aberta", evidenciando a relação com uma espécie de cenário ou palco. A casa é representada como um espaço transitório, por vezes, não há um plano a demarcar o chão - são assumidamente casa de/em papel.

Nestes desenhos, o espaço da casa é feito de cantos e arestas, é subtilmente dividido em vários territórios segundo as várias actividades, as necessidades dos que aí habitam, e o seu papel. Aqui se constroem as primeiras relações afectivas e sociais, a vida neste microcosmo antecipa e condiciona as relações que se tecem mais tarde e, se estendem para o espaço social, externo. A configuração fragmentária do corpo da casa é um duplo do corpo dos personagens, no sentido

9 Tradução da autora. No original: “Ce que je cache avec mon langage, mon corps le dit. (...) Mon corps est un enfant entêté, mon langage est un adulte très civilisé..."

10 Tradução da autora. No original : « (...) tout espace vraiment habité porte l'essence de la notion de maison. » 
em que estas representações simbólicas reflectem características morais e psicológicas dos personagens.

A recorrente duplicação do personagem feminino tem origem numa frase de Henry Bauchau : "je suis peuplée je suis convié"11, que pode ser entendido como "eu sou povoada, eu sou convocada". Contudo, há uma dificuldade em traduzir, nesta circunstância, o verbo "être". Adoptei esta tradução em detrimento de "eu estou povoada, eu estou convocada", evitando a conotação com uma condição temporária.

No âmbito do meu trabalho, esta curta frase resume a situação singular e paradoxal daquele que conta uma estória. Mas "quem" povoa o autor e o convoca a narrar uma estória? O autor seja ele desenhador ou escritor, pode ser habitado por uma necessidade de dar corpo e voz aos personagens e às estórias. Nesse sentido, quem o povoa e habita temporariamente são as personagens, e o desejo de inscrever essa estória no mundo. Ou seja, a produção de uma qualquer narrativa é, antes de mais, um compromisso íntimo que acarreta uma responsabilidade para consigo mesmo, e posteriormente para com o mundo exterior. Je suis peuplée sintetiza um somatório de sensações e experiências acumuladas ao longo de dias e de anos. Ser e estar conscientemente povoado de todos os outros que nos constituem também questiona a verdade dogmática das nossas próprias virtudes - revelando idiossincrasias intrínsecas, e as que nos são imputadas. Por essa razão, a quase totalidade destes personagens femininos são auto-representações, são uma imagem mental, uma repetitiva projecção dos vários aspectos da minha condição feminina. É importante frisar que até ao presente pouco me interessou produzir um auto-retrato mimético per se. Assim, o personagem feminino é representado junto a um duplo e ambos "se desenham" simultaneamente ou no caso de - a um corpo cheio, completo, contrapor-se outro, apenas sugerido. Este duplos-corpos são interdependentes - sem serem necessariamente complementares - tricotam-se, moldam-se e/ou desenham-se um ao outro: entrelaçam as linhas que engendram membros, entranhas, longos cabelos, modelam o peso do corpo que circunscreve a silhueta do outro, esculpem-se. Este binómio, seja um par por oposição, complementaridade ou duplicação pode ser ainda artista-modelo - pretexto para reflectir sobre a relação entre os vários papéis que desempenho quotidianamente e, de certa forma, multiplicar as representações virtuais em torno desta pessoa que pode ser "eu". Diz Roland Barthes que é a mulher que dá uma forma - ou conforma - a ausência, que « desenvolve a ficção, pois ela tem tempo; ela tece e ela canta.» $^{12}$ (Barthes $\left.1977: 20\right)$

É neste espaço liminal que eu, como autor- personagem, sou convocado a produzir um sentido, que chamo e sou chamado.

O meu trabalho é como um mapa de referências e afectos. É uma teia imperceptível, urdida na vivência do dia a dia e que abarca 2 continentes e três línguas. Nunca se fixa. Subscrevo o posicionamento de William Kentridge ${ }^{13}$ quando afirma que, pelo seu grau de intensidade,

11 Bauchau, Henry. 2000 : 41. L'écriture à l'écoute. Bruxelas: Actes Sud.

12 Tradução da autora. No original : « élabore la fiction, car elle en a le temps; elle tisse et elle chante .»

13 "making the work that both clarifies the idea of the work but also, in the end, constitutes who the artist is or who he is (...) and in the end construct the person who has been drawing them." Point of view, an anthology of the moving image, entrevista com Dan Cameron, gravada em 2003 ; "...) in the end the work will be about who you are. It will be revealing of who one is. I think it protects you from the idea of self-knowledge, which you think you are going to express. It opens you up to discovering much more about yourself or about the world." Breidbach, Angela e Kentridge, William. 2006. Thinking aloud. Colónia: Walter Koning 
todas as experiências próprias à vida doméstica ou de atelier constituem-nos simultaneamente enquanto indivíduos e enquanto artistas, e que não há uma separação entre estas duas vivências quotidianas. Acrescento ainda que, mais importante do que ser veículo de auto-conhecimento ou do (possível) factor terapêutico, o trabalho artístico é parte estruturante e fundamental da identidade do indivíduo que é artista.

Os projectos existem a partir de ideias simples, surgem por falha de um outro trabalho, amadurecem lentamente - por via de uns rabiscos e, no caso de objectos, pequenas maquetas; são sempre concebidos numa profunda e estranha simbiose com os trabalhos anteriores e, uma vez materializados, dão origem a outro(s) projecto(s). Arrisco-me a dizer que, também os projectos nunca se fixam, que avançam num processo contínuo e simultâneo a uma lógica interna, biográfica. Todos os personagens vivem numa dualidade cómico-trágica ${ }^{14}$ - esquivando-se a representar o bem e o mal... tudo o que os personagens fazem tem como objectivo sobreviver às suas transformações.

Numa entrevista, Foucault define a sua relação com a escrita dizendo que "escrever é lutar, resistir; escrever é devir; escrever é cartografar (...)" (Deleuze, 1987). Concluo este texto subvertendo e apropriando-me das suas palavras desenhar é lutar, resistir; desenhar é devir; desenhar é cartografar, e o corpo que cartografa e o mundo cartografado alteram-se quotidianamente. É talvez por isso que um artista (ou escritor) dá continuidade ao trabalho, porque a tarefa de cartografar o mais modestos dos mundos é infindável.

\section{Bibliografia}

Al Berto. 2001. O anjo mudo. Lisboa: Assírio \& Alvim.

Bachelard, Gaston. 2001. La poétique de l'espace. Paris: Puf/Quadrige.

Barthes, Roland. 1977. Fragments d'un discours amoureux. Paris: Editions du Seuil.

Bauchau, Henry. 2000. L'écriture à l'écoute. Bruxelas: Actes Sud.

Bettelheim, Bruno. 1998. Psicanálise dos contos de fadas. Lisboa: Bertrand Editora.

Breidbach, Angela e Kentridge, William. 2006. Thinking aloud. Colónia: Walter Koning.

Deleuze, Gilles. 1987. Foucault. Lisboa: Vega.

Gil, José. 2005. Sem Título. Escritos sobre arte e artistas. Lisboa: Relógio d'Água.

Nancy, Jean-Luc. 2004. "Cinquenta e oito indícios sobre o corpo". Revista de Comunicação e linguagens - Corpo, Técnica, Subjectividade, n³3. Relógio d’Água. Lisboa.

Platão. 1986. O Banquete. Mem Martins: Europa-América.

Saramago, José. 1997. “O autor como narrador”. Revista LER no 38, primavera/Verão. Lisboa. Sousa, Ângelo de. 2003. "Refracções”. in, Revista de Comunicação e linguagens - Imagem e vida. no 38 Relógio d’Água, Lisboa.

14 Citando Luísa Neto Jorge: A tua gravidade: o justo peso de que dispóes / para rir. In, Neto Jorge, Luísa. 1993: 139. Poesia. Lisboa: Assírio \& Alvim 


\section{Drawings 2001-2011: Stories and Sketches}

Concise essay on the relationship between drawing and text in the art work of Isabel Baraona. Based on a a number of authors from different fields of study, particular attention is given to two elements common to several series of drawings, developed between 2001 and 2011: the house and duplicated bodies, as proxies for self-representation. This is a personal reflection about drawing and the creative process, and on how an art work can be a cartography of elective affinities.

Keywords: drawing, process, self-representation, story, narrative

Recebido em: 2018-12-12

Aceitado em: 2019-02-27 